\title{
Neues Kombinationspräparat für die initiale Therapie
}

_ Schon bei mäßiger Hypertonie kann eine medikamentöse Therapie die Inzidenz kardiovaskulärer Ereignisse und die Sterblichkeit langfristig senken, betonte Prof. Martin Hausberg, Karlsruhe. Hierfür steht nun ein neues Kombipräparat mit den Wirkstoffen Perindopril und Amlodipin (Viacoram ${ }^{\circledR}$ ) als FirstLine-Therapie anstelle einer Monotherapie zur Verfügung.

Für die initiale Kombination bei Patienten mit erhöhtem Risiko sieht Haus- berg zwei Argumente: Das schnellere Erreichen des Zielblutdruckwerts und die bessere Adhärenz. Dabei empfiehlt die Deutschen Hochdruckliga RAS-Blocker, Kalziumantagonisten und Thiaziddiuretika.

\section{Angepasste initiale Dosierung}

„Wir sollten kombinieren - aber richtig“, betonte auch Prof. Florian Limbourg, Hannover. Die neue Kombination wird einmal täglich eingenommen: zum The-

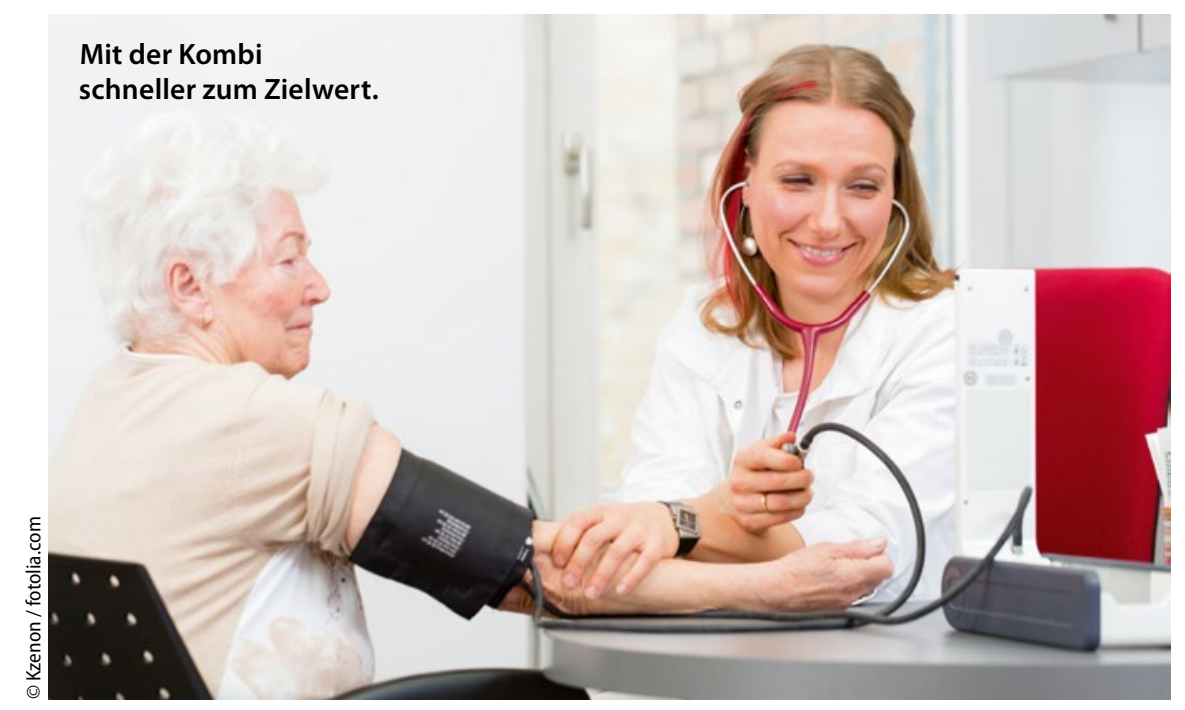

rapiestart in der Dosierung 3,5 mg Perindopril/2,5 mg Amlodipin, anschließend $7 \mathrm{mg} / 5 \mathrm{mg}$. In der ASCOTStudie war sie der Kombination eines Betablockers mit einem Diuretikum bezüglich harter Endpunkte überlegen [ASCOT Investigators. Lancet 2005].

Limbourg berichtete auch, dass die niedrigere Dosis gegenüber den Einzelsubstanzen in höherer Dosierung bei gleichwertiger Blutdrucksenkung deutlich weniger unerwünschte Wirkungen verursache.

Im Vergleich $\mathrm{zu}$ einer klassischen Stufentherapie mit einem Sartan plus Amlodipin erreichten mit der neuen Kombination signifikant mehr Patienten den Zielwert bereits nach einem Monat. Eine Studie über 270 Tage mit über 3.000 Hypertonikern fand unter Perindopril/ Amlodipin eine signifikante Reduktion kombinierter kardiovaskulärer, renaler und metabolischer Endpunkte im Vergleich zu Irbesartan/Hydrochlorothiazid [Poulter NH et al. ESH Expert Meeting 2015].

\section{Dr. Andreas Häckel}

- Frühstückssymposium „Von Anfang an gut eingestellt", 39. Tagung der Deutschen Hochdruckliga; Saarbrücken, 20. November 2015 (Veranstalter: Servier)

\section{Atemwegsinfekte}

\section{Phytotherapeutikum meistens besser als „Resistenzen auf Rezept"}

-90\% der Atemwegsinfekte sind viral bedingt, doch wird immer noch häufig ein Antibiotikum rezeptiert - was die Resistenzproblematik verschärft. Alternativ lohnt es sich, die physiologischen Reinigungsmechanismen zu aktivieren, z. B. durch Gabe des Spezialdestillats ELOM-080 (GeloMyrtol ${ }^{\oplus}$ forte). Seine rein pflanzlichen Inhaltsstoffe erhöhen die Zilienschlagfrequenz und verbessern durch Freisetzung von Chlorid-Ionen gleichzeitig die Fluidität, was die muko- ziliäre Clearance steigert. Die aktuellen DEGAM-Leitlinien empfehlen das Präparat bei akuter und chronischer Sinusitis und Bronchitis.

\section{Red}

